\title{
Interprofissionalismo na Estratégia Saúde da Família: um olhar sobre as ações de promoção de saúde bucal
}

\section{Interprofessionalism in the Family Health Strategy: a look on the actions of promotion of oral health}

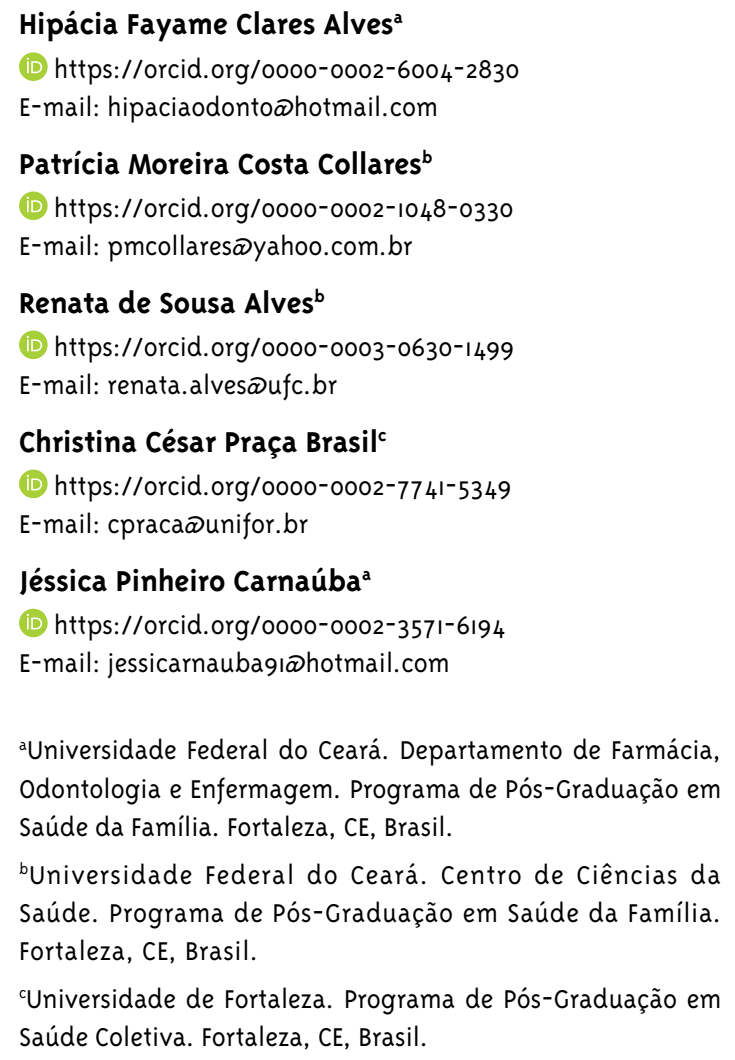

\section{Christina César Praça Brasilc}

(iD) https://orcid.org/0000-0002-7741-5349

E-mail: cpracaœunifor.br

\section{Jéssica Pinheiro Carnaúba ${ }^{a}$}

(iD) https://orcid.org/0000-0002-3571-6194

E-mail: jessicarnaubagı®hotmail.com

anniversidade Federal do Ceará. Departamento de Farmácia, Odontologia e Enfermagem. Programa de Pós-Graduação em Saúde da Família. Fortaleza, CE, Brasil.

buniversidade Federal do Ceará. Centro de Ciências da Saúde. Programa de Pós-Graduação em Saúde da Família. Fortaleza, CE, Brasil.

'Universidade de Fortaleza. Programa de Pós-Graduação em Saúde Coletiva. Fortaleza, CE, Brasil.

\section{Correspondência}

\section{Resumo}

O trabalho interprofissional é necessário para a consolidação do modelo de atenção à saúde, porém o cirurgião-dentista encontra muitos desafios para trabalhar em equipe. Este estudo objetivou conhecer o interprofissionalismo, no âmbito da saúde bucal, entre os trabalhadores graduados da Estratégia Saúde da Família. Tratou-se de um estudo exploratório e transversal, com abordagem qualitativa, desenvolvido com 39 profissionais graduados da Atenção Básica do município de Icó, Ceará, Brasil. Os sujeitos pesquisados declararam uma deficiência na manutenção técnica nas unidades, a recorrente falta de insumos e a demanda excessiva de usuários como elementos que prejudicam o trabalho em equipe, assim como a inexistência de um plano de cargos, carreiras e salários, sendo um motivo de descontentamento entre os profissionais. Todos consideraram importante o trabalho interprofissional e sugeriram reuniões periódicas, atividades compartilhadas mais frequentes e capacitações como forma de intensificar essa ação. Apesar de o trabalho interprofissional ser reconhecido como fundamental para as ações de cuidado, é necessário mais comprometimento e apoio da gestão.

Palavras-chave: Estratégia Saúde da Família; Relações Interprofissionais; Odontologia Comunitária. 


\section{Introdução}

Interprofessional work is necessary for the consolidation of this healthcare model; however, the dental surgeon meet many challenges while working in a team. The objective of this study was to get to know interprofessionalism in the oral health field among the graduated workers of the Family Health Strategy. It was an exploratory and cross-sectional study, with qualitative approach, developed with 39 primary care graduated professionals from the municipality of Icó, state of Ceará, Brazil. The individuals surveyed declared a deficiency in the technical maintenance in the units, the recurring lack of inputs and excessive demand from users as elements that hinder teamwork, as well as the lack of a position, career and salary plan are a reason for discontent among the professionals. All of the participants considered interprofessional work important and suggested periodic meetings, more frequent shared activities and training as a way to intensify this action. Although interprofessional work is recognized as fundamental to care actions, more commitment and management support is needed. Keywords: Family Health Strategy; Interprofessional Relations; Community Dentistry.
O modelo brasileiro de atenção à saúde caracterizase pela conjugação de ações e serviços de promoção, proteção e recuperação da saúde, organizando-se de forma regional e hierarquizada. Sua principal porta de entrada é a Atenção Primária à Saúde (APS), que deve ser a ordenadora da rede de atenção, preferencialmente, por meio da Estratégia Saúde da Família (ESF) (Reis; Scherer; Carcereri, 2015).

Tal estratégia tem como principal objetivo reorganizar a prática na APS, incorporando as propostas da vigilância à saúde, assim como buscando contemplar o princípio da integralidade (Mattos et al., 2014). Ela é operacionalizada mediante a implantação de equipes multiprofissionais em Unidades de Atenção Primária à Saúde (UAPS), as quais abrangem um número definido de famílias localizadas em determinada área (Reis; Scherer; Carcereri, 2015).

A inserção da odontologia na ESF visou a ampliação do acesso da população a esses serviços, garantindo atenção integral e priorizando ações de prevenção e promoção da saúde bucal, por meio do estabelecimento de um vínculo territorial, sendo a equipe constituída por cirurgião-dentista (CD), auxiliar em saúde bucal (ASB) e técnico em saúde bucal (TSB), este último a depender da modalidade (Moraes; Kligerman; Cohen, 2015).

Os Núcleos Ampliados de Saúde da Família e Atenção Básica (NASF-AB), com equipes multiprofissionais, foram constituídos como apoio à ESF, com a grande missão de desenvolver a integralidade e auxiliar no desenvolvimento da interdisciplinaridade (Gonçalves et al., 2015).

Para que o trabalho de saúde bucal na ESF integre toda a equipe de profissionais, buscando o conhecimento integral e a construção coletiva das intervenções, e não apenas articulações pontuais e encaminhamentos internos, é fundamental a compreensão de todos acerca do processo saúdedoença, o que permitirá ampliar a intervenção sobre determinado problema, outrora reservado apenas à atividade do cirurgião-dentista (Ferreira et al., 2014).

Assim, questiona-se: quais são as fragilidades e potencialidades do segmento de ações de promoção de saúde bucal em interface com o trabalho interprofissional na APS? 
Ser multiprofissional é compartilhar um ambiente de trabalho composto por profissionais das várias áreas da saúde, abordando um mesmo paciente a partir de diferentes pontos de vista. Já o interprofissionalismo é a construção do cuidado em colaboração, complementar e coordenada entre os integrantes, tentando superar a especialização profissional, fragmentada, em que o contato com as outras áreas fica restrito a encaminhamentos, não havendo, portanto, uma construção conjunta de avaliação e elaboração de condutas. Dessa forma, o processo que garante a troca de saberes entre a equipe multiprofissional se caracteriza pela relação interprofissional (Peduzzi et al., 2013).

Dentro do interprofissionalismo, existe um meio propício para um cenário de práticas colaborativas, as quais acontecem quando diversos profissionais da saúde com diferentes experiências profissionais trabalham em conjunto com pacientes, familiares, cuidadores e comunidades, um trabalho compartilhado com ações coletivas voltadas a tarefas comuns para prestar assistência de qualidade (Lavôr et al., 2019).

De abril a setembro de 2019 , foi realizada a revisão da literatura de caráter bibliográfico na base de dados MEDLINE, via PubMed e LILACS, utilizando-se os seguintes descritores: Estratégia Saúde da Família; Relações Interprofissionais; Odontologia Comunitária. Foram obtidas produções científicas publicadas no período de 2010 a 2019 que tratavam do interprofissionalismo na ESF, além do uso de livros e documentos do Ministério da Saúde.

Objetivou-se com o presente trabalho conhecer a percepção sobre o interprofissionalismo, no âmbito da saúde bucal, entre os trabalhadores graduados da Estratégia Saúde da Família. Foi analisada, através da escuta dos pesquisados, a compreensão de como acontece esse interprofissionalismo na prática, com suas limitações e potencialidades, podendo assim ser sugerido capacitações antes do trabalhador ingressar na ESF e durante, por meio da Educação Permanente em Saúde.

Justifica-se o estudo nesta conjuntura de adotar, efetivamente, o interprofissionalismo dentro da ESF como primordial para que o trabalho em equipe possa agregar valor dentro das UAPS. As ações interprofissionais, na esfera da saúde bucal, trazem benefícios tanto aos usuários, com a possibilidade de ter seus casos discutidos por diversas áreas da saúde e afins, quanto aos próprios profissionais envolvidos, que em equipe integram mais conhecimento, compreendendo melhor o trabalho dos colegas e, por conseguinte, contribuindo para o vínculo da equipe.

Diante da complexidade do processo saúdedoença, a atuação interprofissional constitui um elemento importante para o desenvolvimento do trabalho em saúde. Embora cada profissional tenha a liberdade para introduzir mudanças necessárias à realidade de cada território, sua ação deve ser articulada com o propósito de cuidar do ser humano (Reis; Scherer; Carcereri, 2015).

\section{Método}

O presente trabalho é um estudo transversal de caráter exploratório com abordagem qualitativa. A pesquisa foi realizada no município de Icó, Ceará, Brasil, localizado na região sudeste do estado. Sendo desenvolvida com os profissionais graduados da área da saúde, que foi um critério de inclusão, de 11 equipes de Saúde da Família (eSF) que possuíam equipe de Saúde Bucal (eSB). Foram excluídos os profissionais contratados recentemente (três meses). Considerou-se também a perda amostral, em casos no qual o(a) profissional estava de licença ou de férias. No período da pesquisa, das 11 equipes da ESF presentes no estudo, três estavam sem médico, uma contava com uma médica recém-contratada, e em outra a cirurgiã-dentista estava de licença; pontuando-se, assim, como um fator limitante do trabalho, por reduzir o tamanho da amostra.

Assim, fizeram parte da pesquisa: médicos (7), enfermeiros (11), cirurgiões-dentistas (10) e os membros constituintes do NASF-AB I e do NASFAB II (ambos com as mesmas características e finalidades): nutricionista (2), fisioterapeuta (2), assistente social (1), profissional de educação física (2), psicólogo (2), terapeuta ocupacional (1) e fonoaudiólogo (1). Totalizando 39 profissionais.

Os instrumentos foram organizados em três blocos temáticos: caracterização do profissional, processo de trabalho e interprofissionalismo em saúde bucal. 0 primeiro bloco continha dois questionários semiestruturados semelhantes que se diferenciavam apenas devido à profissão, visto que 
um foi entregue aos cirurgiões-dentistas e o outro aos demais trabalhadores graduados.

O segundo bloco temático apresentava 13 declarações que variavam ao longo de uma escala Likert: Concordo Totalmente (CT), Concordo (C), Neutro (N), Discordo (D) e Discordo Totalmente (DT). Esse conjunto de perguntas foi adaptado da Autoavaliação para Melhoria do Acesso e da Qualidade (AMAQ) (Brasil, 2017), instrumento utilizado à época pelo Ministério da Saúde no Programa Nacional de Melhoria do Acesso e da Qualidade (PMAQ).

Por fim, o terceiro bloco temático compreendia cinco perguntas abertas que visavam identificar como as relações interprofissionais na promoção de saúde bucal aconteciam na ESF do município de Icó, com a obtenção de sugestões para melhorar o trabalho em equipe. Esse bloco foi adaptado do questionário Readiness for Interprofessional Learning Scale, validado no Brasil (Peduzzi et al., 2015), com o intuito de aproximá-lo à realidade dos trabalhadores da Atenção Básica do município.

Os dados do primeiro e segundo bloco foram tabulados e organizados através do programa Excel versão 2013 e operacionalizados com auxílio do software de análise estatística Statistical Package for the Social Sciences (SPSS) versão 23. Possibilitando a construção, respectivamente, das categorias temáticas: Caracterização sociodemográfica e profissional dos sujeitos da pesquisa e Processo de trabalho associado ao interprofissionalismo.

A análise qualitativa do terceiro bloco foi submetida à análise de conteúdo de Bardin (2011) na modalidade temática (Minayo; Deslandes; Gomes, 2007). A análise de conteúdo é composta pelas fases de pré-exploração do material, seleção das unidades de análise, processo de categorização e subcategorização, e codificação das unidades de análise. Intenciona extrair das diversas respostas seus sentidos e significados principais, confrontando-os com o objetivo do estudo e o referencial teórico. Para facilitar o acesso às fontes de pesquisa e preservar a identidade dos participantes, optou-se pelo uso das profissões, seguido de um número, de acordo com a ordem de aplicação dos questionários.
O resultado da análise fez emergir quatro categorias temáticas: Percepção do interprofissionalismo na Estratégia Saúde da Família;Vínculo da equipe de saúde bucal com a equipe de saúde da família; Limitações para o trabalho interprofissional; e Importância da qualificação para o interprofissionalismo.

O estudo atendeu à Resolução $n^{0} 466$, de 12 de dezembro de 2012, do Conselho Nacional de Saúde e recebeu parecer do Sistema CEP/CONEP de número 3.355.254, em 29 de maio de 2019.

\section{Resultados e discussão}

O interprofissionalismo permite a interação entre os profissionais de diferentes áreas do conhecimento, gerando uma nova configuração interna no ambiente de trabalho, com atitudes complementares, e possibilitando uma atenção à saúde mais ampla, fator essencial para a atenção centrada nas necessidades dos usuários e suas famílias, recurso que alavanca a efetividade dos sistemas de saúde (Reis; Scherer; Carcereri, 2015).

\section{Caracterização sociodemográfica e profissional dos sujeitos da pesquisa}

Observou-se, pela caracterização dos profissionais, que houve uma predominância do sexo feminino, que correspondeu a $69,2 \%$ da amostra, bem como a faixa etária dominante até os 29 anos, com 17 profissionais $(43,6 \%)$, demonstrando um quadro profissional jovem na APS do município.

Com relação ao aspecto da feminização encontrado entre os trabalhadores da ESF, o resultado foi compatível com a literatura, que revelou ser esse fenômeno uma das tendências da área da saúde e, por conseguinte, dos profissionais das equipes de saúde da família (Costa et al., 2013; Oliveira; Bezerra, 2011).

A maior presença de profissionais jovens atuando na Estratégia Saúde da Família pode ser justificada pela mudança curricular nos cursos de graduação. A formação em saúde tem enfatizado a capacitação profissional para atender às reais demandas da Atenção Primária à Saúde e isso pode ter estimulado os recémformados a buscar oportunidade de trabalho junto ao Sistema Único de Saúde (SUS) (Medeiros et al., 2010). 
Quanto à graduação, houve uma equivalência entre faculdades particulares e públicas, com predominância do tempo de graduado em até cinco anos, o que reflete no tempo de atuação na APS, com maior concentração de trabalhadores em até cinco anos também.

Notou-se que há um considerável número de trabalhadores com pós-graduação do tipo especialização em Saúde da Família, 22 profissionais, correspondendo a $56,4 \%$. Porém, a categoria dos cirurgiões-dentistas (CD) é a que menos apresenta esse tipo de pósgraduação (9,1\%), prevalecendo especialização na área clínica (42,9\%). Quando se observa esse maior interesse dos CD em pós-graduações na esfera clínica, isso advém provavelmente da força que essas disciplinas têm na graduação em odontologia e no ideário simbólico da profissão, secundarizando as questões inerentes à saúde coletiva (Moura et al., 2013).

\section{Processo de trabalho associado ao interprofissionalismo}

O presente estudo evidenciou uma avaliação heterogênea quanto aos equipamentos e à infraestrutura das UAPS, por parte dos profissionais de saúde da família. Enquanto 38,5\%, em sua maioria de cirurgiões-dentistas, concordaram que há infraestrutura e equipamentos adequados para a realização de suas ações de saúde; $41 \%$ discordaram, destacando-se com essa visão a maioria dos médicos e dos trabalhadores do NASF-AB.

Quando os profissionais foram questionados se a disponibilidade de insumos é suficiente para o desenvolvimento regular das ações de saúde, 24 dos 39 participantes discordaram, totalizando $61,5 \%$. Isso reflete diretamente nas atividades interprofissionais do cuidado em saúde, tendo em vista que restringe o processo de trabalho.

No que tange à manutenção dos equipamentos odontológicos e demais na Atenção Básica, a maioria dos trabalhadores $(66,7 \%)$ afirmaram não ser garantida, com destaque para a opinião dos cirurgiões-dentistas, evidenciando uma queixa rotineira sobre a necessidade de consertos com grande frequência.
Os resultados sugerem a importância do aprimoramento da infraestrutura e da obtenção de equipamentos e materiais para a realização das práticas em saúde. As deficiências estruturais das UAPS repercutem em insatisfação dos profissionais no trabalho em equipe, uma vez que o modelo de assistência proposto na ESF pressupõe assistência integral, o que requer condições estruturais adequadas para a execução das ações que ultrapassem o modelo biomédico (Oliveira Júnior et al., 2013).

A infraestrutura frágil e a insuficiência de recursos materiais, além de comprometer o desenvolvimento e a qualidade das ações da Atenção Básica, geram desânimo nos profissionais e limitam as potencialidades de ampliação do elenco de ações na perspectiva da reorganização das práticas e do modelo de atenção à saúde (Soares Neto; Machado; Alves, 2016).

A odontologia, mesmo sendo uma profissão antiga no Brasil, ainda é comum não ser priorizada, por envolver grandes custos, uma vez que, para seu devido funcionamento, é necessário um aparato de equipamentos e insumos (Ferreira et al., 2014).

Neste estudo, constatou-se que a maioria dos profissionais da Atenção Básica $(56,4 \%$ ) afirmou não ter seus direitos trabalhistas e previdenciários garantidos. E quando questionados sobre a existência de um Plano de Cargos, Carreiras e Salários no município, quase todos alegaram sua inexistência (89,7\%). Também foi predominante o descontentamento em todas as categorias quanto à ausência de uma adequada distribuição de gratificações, de acordo com metas pactuadas com as equipes, totalizando $71,8 \%$.

Gratificações com incentivo financeiro, quando repassadas aos funcionários das equipes de saúde, promovem a valorização profissional, o que ratifica a importância do trabalho em equipe na busca por resultados enriquecedores, pois trabalhadores satisfeitos tendem a ser mais comprometidos com seu trabalho e mais motivados (Melo et al., 2016).

É necessário proporcionar estabilidade e segurança funcional para que os profissionais desempenhem suas atividades com motivação e empenho. Podendo contribuir para o exercício pleno da liberdade que lhes é conferida para a gestão do próprio trabalho (Reis; Scherer; Carcereri, 2015). 
Entre os participantes, 64,1\% alegaram não existir na APS do município uma Política de Educação Permanente, o que se alinha aos $64,1 \%$ que afirmaram não haver estratégias de educação permanente de acordo com as necessidades dos profissionais.

Quanto à participação em cursos de atualização, qualificação e pós-graduação, 69,2\% dos profissionais declararam não ter dificuldades para serem liberados do trabalho. Apesar da maioria $(58,9 \%)$ ter formação complementar para o trabalho na Atenção Básica, na categoria dos cirurgiões-dentistas, 70\% disseram não ter qualificação para tanto, o que corrobora com o perfil tradicional desses profissionais, mais afeitos a cursos na área clínica.

A Política Nacional de Educação Permanente em Saúde (PNEPS) orienta que a formação e o desenvolvimento de profissionais de saúde, respondendo às demandas do SUS, ocorram de modo descentralizado e ascendente, incluindo todos os locais e saberes, dando acesso à democratização dos espaços de trabalho (Brasil, 2011).

À medida que os profissionais são qualificados, muitas ações podem ser implementadas, melhorando e aumentando o acesso da população aos serviços de saúde. Qualificar trabalhadores com olhar crítico voltado aos problemas locais, procurando soluções exequíveis, apoiadas na gestão e no controle social, favorece as ações de saúde (Medeiros, 2015).

Há uma boa representatividade de todas as categorias profissionais quanto à participação periódica nas reuniões de suas respectivas equipes de saúde: $85,8 \%$ dos médicos, $60 \%$ dos cirurgiõesdentistas, $81,8 \%$ dos enfermeiros e $90,9 \%$ dos profissionais do NASF-AB. Observa-se que os CD apresentaram a menor assiduidade nas reuniões, seja por não se sentirem parte da equipe multiprofissional da UAPS onde atuam (Moraes; Kligerman; Cohen, 2015), seja pela equipe não considerar sua participação relevante (Peruzzo et al., 2018).

Sobre as agendas individuais serem organizadas de modo compartilhado com os demais membros da equipe, entre concordam e concordam totalmente, as categorias de médicos, enfermeiros e profissionais do NASF-AB ultrapassaram os $80 \%$, enquanto os cirurgiões-dentistas atingiram apenas $60 \%$ de concordância.
O espaço das reuniões de equipe é reconhecido pelos profissionais como um ambiente de troca, em que ocorrem planejamento e avaliação das atividades, discussões relativas à operacionalização do serviço, divulgação de informações e discussão de casos. Por fim, acontecem construções coletivas entre os profissionais e, no meio de concordâncias e divergências, são traçados projetos, são assumidos compromissos e são elaborados acordos possíveis (Pereira; Rivera; Artmann, 2013).

Organizar de maneira conjunta com a equipe a programação das atividades interprofissionais garante liberdade e autonomia na estruturação do processo de trabalho, devendo o CD estar inserido nesse planejamento com os diferentes profissionais (Reis; Scherer; Carcereri, 2015).

\section{Percepção do interprofissionalismo na Estratégia Saúde da Família}

Os profissionais foram unânimes em afirmar que o trabalho interprofissional, em particular com a equipe de saúde bucal, contribui para uma melhor assistência à saúde na Estratégia Saúde da Família. Na visão dos profissionais, permite uma complementação da assistência à saúde e garante uma abordagem ampla do processo saúde-doença.

Tanto a área médica quanto a saúde bucal quando mantém uma boa comunicação conseguem combater comorbidades evitáveis (Médica 5).

Cada um sabe como o outro poderá contribuir no manejo do paciente, possibilitando ao paciente um trabalho em equipe e multidisciplinar que atenda todas as suas necessidades (CD 9).

O trabalho interprofissional engrandece a qualidade da assistência prestada. Parceria entre eSF e eSB proporciona notavelmente a melhora dos indicadores de saúde (Enfermeira 3).

O ser humano deve ser visto de uma forma integral e com a colaboração de diversos campos de saberes, essa integralidade pode ser melhor permitida (NASF 5 - Fisioterapeuta). 
Em estudo realizado em um município no estado do Paraná, Brasil, em 2016, também houve a percepção por parte dos profissionais da ESF da importância do trabalho em equipe no atual modelo da Atenção Primária à Saúde, e que alguns aspectos, como comunicação e respeito às particularidades de cada profissão, são essenciais para a manutenção da harmonia e para a implementação de uma prática interprofissional (Peruzzo et al., 2018). No trabalho em equipe, os resultados obtidos são maiores do que a soma dos resultados individuais, aumentando a eficácia e a eficiência do atendimento (Pereira; Rivera; Artmann, 2013).

Sobre as atividades já compartilhadas entre a equipe de saúde bucal e os demais profissionais da equipe de saúde da família, foram reconhecidas: ações educativas do Programa Saúde na Escola (PSE), visitas domiciliares e atividades compartilhadas dentro da Unidade, em especial nas consultas das gestantes e de puericultura.

A visita domiciliar, sobretudo, oportuniza a comunicação interprofissional, pelo fato de maximizar os conhecimentos e as experiências de cada profissional, permitindo que se execute um cuidado coordenado e integrado no domicílio (Previato; Baldissera, 2018).

Estudos apontam que ainda há uma predominância de atividades curativas e preventivas individuais, em detrimento de ações de promoção de saúde coletiva; com a atividade clínica, dentro do consultório odontológico, ocupando a maior parte da carga horária de trabalho dos cirurgiões-dentistas. Apesar de a APS preconizar ênfase nas atividades de prevenção e promoção da saúde, percebe-se que o modelo assistencial permanece vigente (Moraes; Kligerman; Cohen, 2015; Pires; Botazzo, 2015).

\section{Vínculo da equipe de saúde bucal com a equipe de saúde da família}

Alguns profissionais ressaltaram sentir a eSB distante da eSF, como se não a integrassem também, limitando-se às atividades vinculadas ao consultório odontológico, ao invés de apresentarem uma postura mais participativa dentro da unidade.
Seria importante que os profissionais da saúde bucal se apropriassem do universo que é a eSF, e não se limitassem somente a eSB como centro. o grupo de trabalho é imenso, complexo, e toda força contribui para melhoria (Enfermeira 3).

Vejo que alguns profissionais não participam das reuniões de planejamento de trabalho da unidade, pormais que sejam convocados, não sendo formados vínculos que facilitem as relações interprofissionais (Enfermeira 6).

Poderia haver encontros técnicos em que os profissionais de saúde bucal se sentissem efetivamente fazendo parte da eSF, seria abordado planejamento de ações com base em indicadores de saúde e avaliação do planejamento das ações (NASF 6 - Psicóloga).

A incorporação da equipe de saúde bucal trouxe mudanças no âmbito da APS, agregando desafios para o trabalho em equipe, principalmente no tocante às relações interpessoais, como a presença de conflito e o distanciamento entre os membros. Esses desafios podem ser superados com a incorporação de estratégias diversas, como: realização de reuniões periódicas da equipe, conhecimento e valorização do papel de cada integrante e estímulo ao estreitamento do vínculo entre os profissionais (Peruzzo et al., 2018).

Os participantes também foram convidados a sugerir maneiras de tornar a relação interprofissional com a eSB mais próxima, caso julgassem necessário. A partir desse questionamento, propostas foram dadas, salientando a importância das reuniões em equipe e os atendimentos compartilhados, com destaque para algumas falas que se sobressaíram:

Determinação de número de atendimentos compartilhados ao mês e compartilhamento da agenda (Médico 7).

Reuniões periódicas com a equipe, planejamento de atendimentos $e$ atividades coletivas e estudos de caso (CD 6).

Os atendimentos de forma compartilhada ocorrerem com mais frequência em todas UAPS, não sendo 
apenas em alguma de forma pontual (NASF 1 -

Terapeuta ocupacional).

As reuniões de equipe são uma importante estratégia para o estreitamento das relações entre os membros da ESF e para o melhor desempenho e planejamento das atividades. Mais uma alternativa estratégica é permitir que os profissionais conheçam o trabalho de cada um com maior propriedade, de modo que todos possam reconhecer as dificuldades que o outro encontra a partir de suas responsabilidades diárias (Peruzzo et al., 2018).

Recomenda-se explorar as potenciais oportunidades para uma comunicação interprofissional, por meio de reuniões frequentes nas equipes e discussões dos casos, a fim de exercer uma tomada de decisão compartilhada, como preconiza a política que guia a Estratégia Saúde da Família (Previato; Baldissera, 2018).

\section{Limitações para o trabalho interprofissional}

Buscou-se saber a opinião dos profissionais acerca do número de usuários que são atendidos diariamente na ESF, e se de alguma forma a quantidade impossibilitava um melhor trabalho interprofissional junto à equipe de saúde bucal. Os resultados mostraram que poucos trabalhadores não julgaram a demanda nas unidades como empecilho para o trabalho em equipe, acreditando que essa situação seria convertida diante de uma agenda bem organizada e com mais compromisso dos envolvidos. Porém, a grande maioria percebe de maneira diferente:

O número exorbitante de pacientes para atender em cada turno impossibilita uma pausa para planificar estratégias e discutir casos em conjunto com a equipe de saúde bucal (Médica 5).

A quantidade exorbitante de famílias impossibilita o tratamento concluído e as ações integrais (CD 6).

A grande demanda dificulta o processo de trabalho interprofissional. Dificulta principalmente em desenvolver estratégias/ações voltadas à prevenção e promoção, não só em relação à saúde bucal, de forma geral (Enfermeiro 11).
A alta demanda limita o tempo para dispor de uma consulta ou atendimento mais qualificado e interprofissional, pois este trabalho exige um tempo maior para sua execução, bem como disponibilidade simultânea dos profissionais. A consulta compartilhada, por exemplo, requer uma discussão anterior do caso, um momento com o próprio usuário, bem como reuniões posteriores para discussão e definição das metase prosseguimento do caso. (NASF 5 - Fisioterapeuta)

A grande demanda acumulada, a sobrecarga de trabalho e a falta de tempo disponível são importantes barreiras para o trabalho compartilhado e a integração entre os profissionais no âmbito da saúde bucal nas UAPS. Há a necessidade de mecanismos institucionais, traduzidos em ações em nível de gestão que possam permitir essas práticas integradas (Moraes; Kligerman; Cohen, 2015).

O próprio processo histórico de inserção da saúde bucal na ESF, a formação acadêmica dos profissionais, os programas ministeriais, os aspectos estruturais e as concepções acerca da Educação em Saúde confluem para a organização de um processo de trabalho que privilegia o modelo tradicional de educação, o que faz com que este permaneça hegemônico nas práticas atuais (Mendes et al., 2017).

As exigências e as cobranças presentes nos serviços de saúde, como melhorar indicadores de saúde e o número de procedimentos, podem burocratizar o atendimento em saúde e culminar em dificuldades para manter o diálogo entre as categorias profissionais, debilitando, por conseguinte, a comunicação interprofissional (Jorge et al., 2014).

\section{Importância da qualificação para o interprofissionalismo}

Por fim, outra questão levantada foi sobre a importância de uma capacitação antes de ingressar na ESF, bem como de um acompanhamento através da educação permanente como dispositivo para o trabalho interprofissional, não restando dúvidas entre todos os trabalhadores, das diversas categorias, sobre a contribuição de uma qualificação prévia e também contínua na Atenção Primária à Saúde. 
A capacitação é primordial para a inserção do profissional no mundo do SUS, pois este já chega habilitado e consciente das ações e princípios do SUS, para assim aplicá-los de modo correto. Ex.: PET-Saúde que habilita os estudantes a conhecer a ESF e vivenciar o território com os agentes comunitários de saúde e a rotina de trabalho da equipe. (CD 6)

A capacitação, de maneira geral, já começava como uma ótima estratégia para inserir o profissional dentro do seu ambiente de trabalho, visto que ESF é um processo contínuo e de vínculo com sua população adscrita, que de maneira alguma deve ser feito individualmente. (Enfermeiro 11)

Preparando os profissionais para atuarem na Atenção Básica, favorecendo o conhecimento das ferramentas de trabalho utilizadas nesse nivel de atenção (NASF 3 - Fisioterapeuta).

A capacitação seria uma forma de sensibilizar os profissionais quanto à importância desse tipo de trabalho, bem como uma forma de qualificá-los no desenvolvimento das ações, podendo ser um direcionamento do que pode ser executado entre as diversas especialidades e para casos específicos da Atenção Primária. (NASF 5 - Fisioterapeuta)

Super importante, muitos profissionais saem da faculdade sem a noção real do que é trabalhar com saúde coletiva, assim como o processo de educação permanente favorece um trabalho em equipe mais integrado, com indicadores de saúde do território, avaliação, planejamento, enfim só se ganha com qualificação constante e contínua. (NASF 6 - Psicóloga)

Estudos trazem que os profissionais da ESF, por vezes, consideram insuficientes seus conhecimentos sobre como trabalhar conceitos relativos aos princípios ordenadores da Atenção Básica, como planejamento, monitoramento e avaliação; indicadores; processo de trabalho em equipe; e organização da demanda, aprendendo com a rotina e colegas de trabalho (Reis; Scherer; Carcereri, 2015; Moura et al., 2013).
A inclusão do profissional cirurgião-dentista na ESF confronta sua formação tradicional de saber fragmentado, comum também entre os demais profissionais da saúde, o que representa um desafio para o trabalho interprofissional. Porém, quando eles possuem formação continuada no contexto da saúde coletiva e da família, conseguem estabelecer a integração no trabalho em equipe, o entendimento a partir do trabalho interprofissional e a valorização das competências profissionais comuns (Peruzzo et al., 2018).

Assim, iniciativas interprofissionais deveriam estar presentes em diferentes momentos da formação dos profissionais da saúde, durante e após a graduação, devendo ser estimuladas ainda na universidade. Quando se permite a interação de estudantes de diferentes ofícios, utilizando-se metodologias ativas de ensino-aprendizagemavaliação, há uma maior disponibilidade para aprendizagem compartilhada e trabalho em equipe (Nuto et al., 2017).

A educação profissional ainda é desenvolvida por meio da oferta de capacitações e treinamentos, apoiada no saber biomédico e fundamentada em abordagem metodológica vertical de transmissão de informação. O propósito, geralmente, é de atualização de procedimentos e protocolos, baseando-se nas recomendações estabelecidas pelo Ministério da Saúde ou pela Secretaria Estadual de Saúde (Bispo Júnior; Moreira, 2017).

Ao contrário dessa, a educação permanente em saúde é caracterizada pela relação aprendizagemtrabalho, que ocorre no cotidiano dos serviços de saúde, em que o aprender e o ensinar se incorporam aos processos de trabalho, sendo fatores indissociáveis na rotina dos serviços e na interação entre os profissionais (Batista; Gonçalves, 2011; Siqueira-Batista et al., 2015).

\section{Considerações finais}

Diante do exposto, foi possível verificar que, embora as ações interprofissionais sejam reconhecidas pelos profissionais como importante instrumento para o fortalecimento das ações de cuidado, ainda há a necessidade da participação mais efetiva dos cirurgiões-dentistas nesse processo, 
inclusive, a própria relação multiprofissional encontra-se enfraquecida.

Os pontos considerados limitantes para a prática interprofissional foram a demanda excessiva de usuários - que ultrapassa o número de famílias preconizado pelo Ministério da Saúde - e a própria postura da equipe de saúde bucal, que nem sempre se apropria da realidade da ESF.

Restrições no processo de trabalho, como a falta de manutenção técnica dos equipamentos das unidades e a carência dos insumos para realização dos procedimentos e atividades coletivas, afetam as ações interprofissionais de promoção da saúde. Além disso, a inexistência de um Plano de Cargos, Carreiras e Salários gera um descontentamento entre os profissionais da ESF do município, o que também poderia justificar o reduzido número de ações entre as categorias.

Como estratégias de fortalecimento das relações interprofissionais na ESF, destacam-se as reuniões em equipe frequentes em todas as unidades, além da determinação de uma quantidade de atendimentos compartilhados. Para tanto, é imprescindível que haja ações interprofissionais ainda na graduação, com continuidade ao longo da carreira do profissional, por meio da educação permanente, bem como o comprometimento individual desses trabalhadores e o apoio da gestão, para sua efetivação.

\section{Referências}

BARDIN, L. Análise de conteúdo. Lisboa: Edições 70, 2011.

BATISTA, K. B. C.; GONÇALVES, O. S. J. Formação dos profissionais de saúde para o SUS: significado e cuidado. Saúde e Sociedade, São Paulo, v. 20, n. 4, p. 884-899, 2011.

BISPO JÚNIOR, J. P.; MOREIRA, D. C. Educação permanente e apoio matricial: formação, vivências e práticas dos profissionais dos núcleos de apoio à saúde da família e das equipes apoiadas. Cadernos de Saúde Pública, Rio de Janeiro, v. 33, n. 9, eoo1o8116, 2017.

BRASIL. Ministério da Saúde. Passo a passo PSE programa saúde na escola: tecendo caminhos da intersetorialidade. Brasília, DF, 2011.
BRASIL. Ministério da Saúde. Autoavaliação para melhoria do acesso e da qualidade da atenção básica-AMAQ. Brasília, DF, 2017.

COSTA, S. M. et al. Perfil do profissional de nível superior nas equipes da estratégia saúde da família em Montes Claros, Minas Gerais, Brasil. Revista Brasileira de Medicina de Família e Comunidade, Rio de Janeiro, v. 8, n. 27, p. 90-96, 2013.

FERREIRA, G. C. et al. Inclusão da odontologia no programa saúde da família (PSF). Revista Odontológica do Planalto Central, Gama, v. 4, n. 1, p. 40-44, 2014.

GONÇALVES, R. M. A. et al. Estudo do trabalho em núcleos de apoio à saúde da família (NASF), São Paulo, Brasil. Revista Brasileira de Saúde Ocupacional, São Paulo, v. 40, n. 131, p. 59-74, 2015.

JORGE, M. S. B. et al. Possibilidades e desafios do apoio matricial na atenção básica: percepções dos profissionais. Psicologia: Teoria e Prática, São Paulo, v. 16, n. 2, p. 63-74, 2014.

LAVÔR, T. B. S. L. et al. Práticas colaborativas e interprofissional na terapia intensiva: conhecimento, reflexos e limitações. Revista Interdisciplinar de Estudos em Saúde, Caçador, v. 8, n. 1, p. 11-27, 2019.

MATTOS, G. C. M. et al. A inclusão da equipe de saúde bucal na estratégia saúde da família: entraves, avanços e desafios. Ciência \& Saúde Coletiva, Rio de Janeiro, v. 19, n. 2, p. 373-378, 2014.

MEDEIROS, C. R. G. et al. A rotatividade de enfermeiros e médicos: um impasse na implementação da estratégia de saúde da família. Ciência \& Saúde Coletiva, Rio de Janeiro, v. 15, p. 1521-1531, 2010. Suplemento 1.

MEDEIROS, L. C. M. Educação permanente como instrumento de mudança na rede de atenção à saúde com foco na estratégia saúde da família: um relato de experiência. Revista Ciência Plural, Natal, v. 1, n. 1, p. 65-74, 2015.

MELO, L. M. L. L. et al. A construção de uma agenda de gestão compartilhada para a reorganização da demanda em saúde bucal. Revista Ciência Plural, Natal, v. 2, n. 1, p. 42-55, 2016. 
MENDES, J. D. R. et al. Análise das atividades de educação em saúde realizadas pelas equipes de saúde bucal. Revista Brasileira em Promoção da Saúde, Fortaleza, v. 30, n. 1, p. 13-21, 2017.

MINAYO, M. C. S.; DESLANDES, S. F.; GOMES, R. Pesquisa social: teoria, método e criatividade. 26. ed. Petrópolis: Vozes, 2007.

MORAES, L. B.; KLIGERMAN, D. C.; COHEN, S. C. Análise do perfil sociodemográfico e do processo de trabalho do cirurgião-dentista inserido no programa de saúde da família em três municípios da região serrana do estado do Rio de Janeiro. Physis: Revista de Saúde Coletiva, Rio de Janeiro, v. 25, n. 1, p. 171-186, 2015.

MOURA, M. S. et al. Saúde bucal na estratégia de saúde da família em um colegiado gestor regional do estado do Piauí. Ciência \& Saúde Coletiva, Rio de Janeiro, v. 18, n. 2, p. 471-48o, 2013.

NUTO, S. A. S. et al. Avaliação da disponibilidade para aprendizagem interprofissional de estudantes de ciências da saúde. Revista Brasileira de Educação Médica, Rio de Janeiro, v. 41, n. 1, p. 50-57, 2017.

OLIVEIRA JÚNIOR, R. G. et al. Condições de trabalho das equipes de saúde da família do município de Petrolina-PE: percepção dos profissionais de saúde. O Mundo da Saúde, São Paulo, v. 37, n. 4, p. 433-438, 2013.

OLIVEIRA, W. M. A; BEZERRA, A. L. Q. Autoavaliação da Estratégia Saúde da Família por enfermeiros. Revista Enfermagem UERJ, Rio de Janeiro, v. 19, n. 1, p. 20-25, 2011.

PEDUZZI, M. et al. Educação interprofissional: formação de profissionais de saúde para o trabalho em equipe com foco nos usuários. Revista da Escola de Enfermagem da USP, São Paulo, v. 47, n. 4, p. 977-983, 2013.
PEDUZZI, M. et al. Adaptação transcultural e validação da Readiness for Interprofessional Learning Scale no Brasil. Revista da Escola de Enfermagem da USP, São Paulo, v. 49, n. 2, p. 7-15, 2015. Edição especial.

PEREIRA, R. C. A.; RIVERA, F. J. U.; ARTMANN, E. O trabalho multiprofissional na Estratégia Saúde da Família: estudo sobre modalidades de equipes. Interface: Comunicação, Saúde, Educação, Botucatu, v. 17, n. 45, p. 327-340, 2013.

PERUZZO, H. E. et al. Os desafios de se trabalhar em equipe na Estratégia Saúde da Família. Escola Anna Nery, Rio de Janeiro, v. 22, n. 4, e20170372, 2018.

PIRES, F. S.; BOTAZZO, C. Organização tecnológica do trabalho em saúde bucal no SUS: uma arqueologia da política nacional de saúde bucal. Saúde e Sociedade, São Paulo, v. 24, n. 1, p. 273-284, 2015 .

PREVIATO, G. F; BALDISSERA, V. D. A. A comunicação na perspectiva dialógica da prática interprofissional colaborativa em saúde na Atenção Primária à Saúde. Interface: Comunicação, Saúde, Educação, Botucatu, v. 22, p. 1535-1547, 2018. Suplemento 2.

REIS, W. G.; SCHERER, M. D. A.; CARCERERI, D. L. O trabalho do cirurgião-dentista na Atenção Primária à Saúde: entre o prescrito e o real. Saúde em Debate, Rio de Janeiro, v. 39, n. 104, p. 56-64, 2015.

SIQUEIRA-BATISTA, R. et al. (Bio)ética e Estratégia Saúde da Família: mapeando problemas. Saúde e Sociedade, São Paulo, v. 24, n. 1, p.113-128, 2015.

SOARES NETO, J. J.; MACHADO, M. H.; ALVES, C. B. The Mais Médicos (More Doctors) program, the infrastructure of primary health units and the municipal human development index. Ciência \& Saúde Coletiva, Rio de Janeiro, v. 21, n. 9, p. 2709-2718, 2016.

\section{Contribuição dos autores}

Clares Alves concebeu o estudo, analisou os dados e redigiu o artigo. Collares concebeu o estudo e redigiu o artigo. Sousa Alves e Brasil analisaram os dados. Carnaúba redigiu o artigo.

Recebido: $18 / 01 / 2021$

Aprovado: 16/03/2021 